\title{
La participación del capital privado en el financiamiento de servicios públicos: el caso de los distritos municipales de Antioquia (Colombia), 1912-1931
}

\section{Private Capital Investment in Public Services Financing: The Case of the Municipal Districts of Antioquia (Colombia), $1912-1931$}

\author{
Ma. Mercedes Botero $1, *$ iD 0000-0003-4423-0572
}

${ }^{1}$ Universidad de Antioquia, Medellín, Colombia.

*Correspondencia: maria.botero9@gmail.com

Resumen. Este artículo tiene como objetivo mostrar un caso de la inversión para la provisión y mejoramiento de servicios públicos en distritos municipales de Antioquia y su financiamiento por parte del capital privado. Con tal fin se examinan los empréstitos otorgados por parte de una casa comercial-bancaria de Medellín, y en especial por uno de sus socios, en el periodo 1912-1931. Dicha firma obtuvo créditos de bancos extranjeros, recursos que canalizaron a numerosos distritos municipales. El texto revela hechos que tuvieron importancia en el crecimiento de Antioquia, esto es, el flujo de capital extranjero, así como el papel que desempeñaron intermediarios financieros de Medellín, los cuales facilitaron su ingreso en el circuito financiero local.

Palabras clave: historia regional; Gran Depresión; capital extranjero; deuda pública.

CÓMO CITAR: Botero, M. M. (2022). La participación del capital privado en el financiamiento de servicios públicos: el caso de los distritos municipales de Antioquia (Colombia), 1912-1931. América Latina en la Historia Económica, 29(1), 1-24. DOI: $10.18232 / 20073496.1251$ 
Abstract. In this paper I analyze the growth of credit that took place in many municipalities in the department of Antioquia (1912-1930). Credits were offered by a wealthy Brokerage House which at the time had abandoned foreign trade and was investing its profits in urban business and banking. Long time relations established with foreign banks allowed the commercial house to benefit from foreign loans, sums of money that were channeled to the region, and were intended to promote the development of public service infrastructure in rural areas. The article shows the flow of foreign capital into the region and the role played by financial intermediaries in Medellin which facilitated its entry into local financial circuits.

Key words: regional history; Great Depression; foreign capital; public debt.

JEL: N26; N36.

Recibido: 22 de septiembre de 2020.

Aceptado: 20 de abril de 2021.

Publicado: 12 de agosto de 2021.

Agradecimiento: Agradezco a Patricia Bachmann por su ayuda en la recolección de la información, así como sus observaciones. A Jaime Vallecilla por sus comentarios. A María Cristina Echeverri, María Isabel Duarte, directora de la Sala de Patrimonio Documental, Centro Cultural Biblioteca Luis Echavarría Villegas, Universidad EAfrT, Medellín; a Claudia, así como todo el personal que procuró la consulta de los archivos y fuentes bibliográficas utilizadas en este trabajo. Mis agradecimientos al personal del Archivo Histórico de Antioquia por su colaboración. Por último, a los dos evaluadores anónimos, gracias.

\section{INTRODUCCIÓN}

En agosto de 1932, en medio de la crisis económica que enfrentaba el país debido a la Gran Depresión mundial, falleció Emilio Restrepo Callejas, un rico y conocido hombre de negocios de Medellín, la capital del departamento de Antioquia. ${ }^{1}$ Una vez abierta la sucesión, se encontró que una parte muy importante y valiosa de sus bienes estaba representada en créditos contra más de 50 distritos municipales de los departamentos de Antioquia y Caldas, por una cantidad superior a 1000000 de pesos oro. ${ }^{2}$ Estos distritos llevaban un tiempo sin poder cumplir con sus obligaciones y se hallaban sumidos en condiciones fiscales adversas.

Dicha situación no constituye un hecho aislado, sino un signo evidente de la crisis que se advertía en la nación, los departamentos y municipios luego de un periodo de prosperidad exportadora y crediticia. Según lo explicaba en 1932 el entonces ministro de Hacienda, "la enorme expansión del crédito que tuvo lugar hasta 1929 trajo un incremento grande de las deudas públicas. Se obtuvieron cuantiosos empréstitos aprovechando las facilidades que se les brindaban en los centros financieros, especialmente en Estados Unidos" (Jaramillo, 1932, p. 24).

Las primeras décadas del siglo xx estuvieron marcadas por transformaciones económicas, políticas y sociales en Colombia. Un hecho decisivo fue el desarrollo exportador exitoso con base en la economía cafetera que tuvo como epicentro la zona occidental del país. En su momento, se inició un proceso de industrialización debido a la ampliación del mercado interno generado por la bonanza exportadora.

Los sucesos que tuvieron lugar a lo largo de estos años han sido asuntos ampliamente estudiados por la historiografía económica colombiana. Se han examinado, entre otros, la expansión cafetera, el balance industrial y las finanzas públicas de las dos primeras décadas del siglo xx. Asi-

${ }^{1}$ Certificado de defunción de Emilio Restrepo. Notaría 3, Libro de Escrituras núm. 1407, 17 de septiembre de 1932. Archivo Histórico de Antioquia, Medellín, Colombia (en adelante AHA).

${ }^{2}$ Arreglo entre municipios y herederos de Emilio Restrepo. Notaría 2, Escritura. núm. 194, 27 de enero de 1934 . AHA. 
mismo, han merecido especial atención por parte de investigadores la expansión del crédito y la llegada de grandes cantidades de dólares sin precedente a Colombia en la década de los años veinte que permitieron financiar la expansión de las obras públicas, hasta la crisis que se generó a partir de la Gran Depresión mundial. ${ }^{3} \mathrm{Si}$ bien estos estudios dan cuenta de lo ocurrido a nivel nacional, aún se conoce muy poco acerca del papel que desempeñó el crédito (externo e interno), así como los problemas de deuda pública que afectaron concretamente a los distritos municipales. El análisis de estos hechos tiene una gran importancia ya que, según afirman varios estudiosos, dichas entidades territoriales también participaron en la fiebre de endeudamiento que alcanzó su pico entre 1926 y 1928, un periodo conocido en la historiografía como el de la prosperidad al debe. ${ }^{4}$ En efecto, según un estudio de Avella (2004), "en conjunto los departamentos y municipios fueron responsables por cerca de la mitad (48\%) del endeudamiento total en Estados Unidos” (p. 178). ${ }^{5}$ Además, de acuerdo con Echavarría (1982), la importancia de los departamentos y municipios en la deuda fue mayor en Colombia (43\% entre 1922 y 1933) que en Brasil, Argentina, Perú o Chile.

Este trabajo busca revelar hechos desconocidos hasta ahora en la historiografía de Antioquia, en relación con la expansión que tuvo el crédito en el ámbito local. Con tal fin, se examina el caso de los empréstitos otorgados a numerosos distritos municipales de Antioquia por parte de una casa bancaria y comercial de Medellín y en particular por parte de uno de sus socios. ${ }^{6}$ Como parte del estudio se analiza, entre otros, la fuente y el modo de financiamiento de los proyectos emprendidos por las autoridades municipales, el papel que desempeñó la banca extranjera, así como el de los intermediarios financieros de Medellín y el uso y destino que se dio a los empréstitos. Se busca señalar, además, la forma como se resolvió y se reestructuró el pago de la deuda entre los municipios deudores y sus acreedores a comienzos de la década de 1930, partiendo del acuerdo al que se llegó. ${ }^{7}$

Se espera, además, que este artículo fomente el interés por investigar temas que no han sido suficientemente explorados en la historiografía de esta región, como son el papel del crédito en el crecimiento económico, en especial el del capital extranjero, el surgimiento de un mercado de capitales en Medellín, y el papel que desempeñaron las instituciones financieras locales, todo ello

${ }^{3}$ Entre otros, véanse Avella (2004); Bernal (1984); Echavarría (1982); Patiño (1981); Pérez (2012); Sánchez (1994); Tovar (1984).

${ }^{4}$ De acuerdo con Patiño (1981), la expresión prosperidad al debe “apareció por primera vez en un artículo de Alfonso López P. publicado en el diario El Tiempo el 10 de junio de 1928. Expresó su preocupación con el endeudamiento externo y su temor de que se estuviese sobrepasando los límites de la prudencia” (p. 50).

${ }^{5}$ El trabajo de Avella (2004) fue de gran ayuda para el desarrollo del presente estudio.

${ }^{6}$ La información acerca de los empréstitos otorgados por los señores Restrepo a los distritos municipales la obtuve hace muchísimos años. Como asistente de investigación del doctor Juan José Echavarría, realicé una entrevista a la señora Pepa Restrepo de Álvarez, nieta de Emilio Restrepo Callejas. Fue ella quien me explicó todo lo relacionado con los empréstitos. En su opinión el financiamiento a los distritos municipales había sido uno de los negocios más importantes de su abuelo. A raíz de las discusiones que se dieron en Colombia en 2018, con los denominados bonos de agua un mecanismo pensado para financiar proyectos de agua potable en los municipios, con recursos de inversionistas privados-, decidí escribir este artículo con el fin de ilustrar un caso que se había presentado a comienzos del siglo xx en Antioquia, esto es, el financiamiento de proyectos de servicio público con recursos del capital privado.

${ }^{7}$ Los préstamos otorgados a los distritos municipales en el departamento de Caldas no son objeto de este estudio. 
enmarcado en el examen de las fuentes básicas de los recursos para el financiamiento y desarrollo de numerosas obras públicas que se llevaron a cabo en el departamento como en Medellín en las primeras décadas del siglo xx. ${ }^{8}$

El trabajo se centra en los años que pasaron entre 1912-1931 en los que, como es bien conocido, se produjo la expansión de la economía cafetera en Antioquia, departamento que, junto a Caldas, se constituyó como el principal productor y exportador del grano. En estos años se dio un gran impulso a las obras públicas: particularmente al Ferrocarril de Antioquia y al Ferrocarril de Amagá. En Medellín, por ejemplo, surgieron las primeras empresas fabriles y la ciudad asistió a un proceso de urbanización (Arango, 1977; Botero, 2003; Brew, 1977).

La documentación consultada para esta investigación proviene de fuentes primarias, entre otras, de la comunicación personal de los socios de la casa comercial Hijos de Fernando Restrepo \& Cía. ${ }^{9}$ No obstante, la mayor parte de la información procede de la consulta realizada en el Fondo Notarial localizado en el Archivo Histórico de Antioquia. Se localizaron las 96 escrituras que se firmaron entre los distritos municipales y los acreedores y se construyó un cuadro en el que figura el número de cada escritura, el nombre del personero que actuó como representante del distrito municipal, el representante legal de la casa comercial Hijos de Fernando Restrepo \& Cía. (o el señor Emilio Restrepo actuando a nombre propio), ${ }^{10}$ el monto del empréstito, la forma de pago, los intereses y los plazos pactados, los bienes otorgados en garantía, así como el uso y destino de cada empréstito.

Una escritura de gran valor documental es la que tiene que ver con el contrato celebrado en 1934 entre los distritos municipales deudores y la sucesión del señor Emilio Restrepo. ${ }^{11}$ Se trata de un largo documento en el que se detallan los pormenores del acuerdo. Allí aparece el nombre del representante de cada uno de los distritos municipales que firmaron el arreglo; las rentas que durante el año de 1932 produjeron en conjunto a los distritos municipales una entrada de dinero; el saldo líquido que cada una de las entidades municipales declararon deber el día 20 de junio de 1933 a favor de la sucesión del señor Restrepo; las cuotas mensuales acordadas, que las entidades deudoras debían pagar mensualmente para el cumplido servicio de sus obligaciones, y el plazo para la amortización total de la deuda, así como la tasa de interés. Como se explicará en la segunda parte de este trabajo, aparece también todo lo relacionado con la emisión de bonos que se llevó a cabo por el monto total de la deuda, así como las entidades que tomaron parte en el arreglo. También, se consultaron algunos documentos públicos de la época localizados en este mismo archivo. Asimismo, se examinó un periódico liberal de Medellín, El Diario, de 1930 a 1934. Toda la información anterior se complementó con fuentes secundarias.

Este artículo está dividido en dos partes. En la primera sección se explica brevemente la expansión bancaria y financiera que tuvo lugar en Antioquia entre 1900 y 1920 y la importancia que conservaban las casas mercantiles bancarias de Medellín. A partir de allí, se examina la participación de la casa comercial Hijos de Fernando Restrepo \& Cía. en el financiamiento de proyectos de

${ }^{8}$ Pérez (2012) concede mucha importancia a la manera como se modernizó el sector financiero en Colombia y la forma como fue complementario del proceso de desarrollo nacional. A su vez, Hanley (2005) examina el papel que desempeñaron el mercado de capitales y las instituciones financieras en el desarrollo económico de Sao Paulo (Brasil).

${ }^{9}$ El archivo de esta casa comercial se encuentra en Medellín y lo conserva un descendiente de los señores Restrepo.

${ }^{10}$ De 1912 a 1921 los préstamos fueron otorgados por la casa comercial Hijos de Fernando Restrepo \& Cía. A partir de 1921, el negocio lo continuó Emilio Restrepo en ocasiones con su hermano Lázaro Restrepo.

${ }^{11}$ Arreglo entre algunos municipios y los herederos de Emilio Restrepo C. Notaría 2. Escritura núm. 194, 27 de enero de 1934. AHA. 
obras públicas en distritos municipales, mostrando la evolución en el tiempo, el número y valor, su uso y destino, el plazo y la tasa de interés. En la segunda parte se examina el arreglo al que llegaron los distritos municipales y los herederos del señor Emilio Restrepo en $1934 .^{12}$

\section{Casas comerciales bancarias en Antioquia a Comienzos del siglo XX}

\section{Comerciantes y prestamistas}

Como parte de los cambios y transformaciones que habían comenzado a insinuarse en Antioquia a la vuelta del siglo xx, la banca privada presentó un fuerte desarrollo. Se crearon nuevos bancos comerciales y se instalaron bancos extranjeros en Medellín. Tanto el Banco de Sucre y el Banco Alemán Antioqueño fueron promovidos por socios de importantes casas comerciales y estuvieron vinculados especialmente al sector externo. Sus principales clientes en este periodo fueron las casas comerciales importadoras y las firmas exportadoras de café. Ambas instituciones tuvieron un papel determinante en esta etapa de crecimiento económico. ${ }^{13}$

A pesar del surgimiento de nuevas instituciones bancarias, así como de la llegada de bancos extranjeros, ${ }^{14}$ grandes casas comerciales-bancarias continuaban teniendo presencia en la actividad bancaria y financiera de la época. Dichas sociedades constituían un modelo de organización que había operado exitosamente en la vida económica de Antioquia en el siglo xix. En general, se trataba de sociedades conformadas por miembros de una o varias familias, unidas y vinculadas entre sí a través de una compleja e intrincada red de relaciones creadas por el vínculo matrimonial, los lazos consanguíneos y/o de negocios. Entre este tipo de sociedades que ejercían actividades comerciales, bancarias y financieras, se encontraba Hijos de Fernando Restrepo \& Cía. (Gaviria, 1923). ${ }^{15}$

Don Fernando, su fundador, se inició en la vida mercantil en la década de 1830 al introducir mercancías inglesas compradas en la isla de Jamaica. A mediados del siglo XIX, estableció relaciones comerciales directamente con firmas en Londres y Manchester, a las que remitía barras de oro. En 1868 conformó en Medellín una sociedad comercial con sus hijos bajo la razón social Fernando Restrepo e Hijos. ${ }^{16}$ Su casa comercial se dedicaba principalmente a la exportación de barras de oro a Inglaterra y a la importación y distribución al por mayor de mercancías inglesas (principalmente textiles), actuando, además, como el agente comercial y representante legal en Medellín de una empresa minera británica, Western Andes Mining Co., dedicada a la explotación de plata en Marmato (estado del Cauca). Esto le facilitó establecer relaciones con importantes ca-

${ }^{12}$ Con base en las Ordenanzas 13 de 1916 y 21 de 1933, la Gobernación prestó atención a la negociación iniciada con los acreedores de los municipios del departamento (Gaceta Departamental de Antioquia, 1934, núm. 4179).

13 Para unn examen de la banca en Antioquia a comienzos el siglo xx, véanse Botero (1994, 2012).

${ }^{14}$ De acuerdo con el informe de Bell (1921), el desarrollo bancario y la oferta de capitales en Medellín eran insuficientes para la magnitud de los negocios. Este autor sostiene que ello favoreció la entrada de bancos extranjeros después de la primera guerra mundial, tales como el Banco de Londres y América del Sur.

${ }^{15}$ En los primeros años del siglo xx existían en Medellín las siguientes sociedades colectivas que se ocupaban de negocios bancarios: Vásquez Correas \& Cía.; Restrepo \& Cía.; Luis María Botero e Hijos; Miguel y Carlos Vásquez \& Cía. e Hijos de Fernando Restrepo \& Cía. (Gaviria, 1923).

16 Notaría 1, núm. 230, abril de 1868. AHA. 
sas bancarias londinenses; entre ellas se encontraba Fruhling \& Goschen, una firma encargada de recibir y vender el metal de la empresa en Londres y de la que Fernando Restrepo e Hijos obtuvo créditos. ${ }^{17}$

El fundador de la firma falleció en 1899. Ese mismo año se cambió la razón social por la de Hijos de Fernando Restrepo \& Cía. ${ }^{18}$ A la vuelta del siglo, sus socios promovieron y fundaron una de las primeras fábricas de textiles en Medellín, la Compañía de Tejidos de Bello. ${ }^{19}$ La correspondencia comercial de la firma sugiere que ya desde comienzos del siglo xx sus socios pensaban abandonar el comercio de importación. En innumerables cartas que enviaron a sus antiguos proveedores en Inglaterra, les comunicaban que habían decidido centrar sus negocios en la Compañía de Tejidos de Bello, pues eran los principales accionistas y administradores, y en otras actividades de tipo bancario: "Ante la mala situación del comercio, hemos comprometido el capital en importantes empresas industriales y en la Banca en las cuales hemos obtenido mejor remuneración." 20

Por tanto, más que aprovechar sus líneas de créditos en el exterior con el fin de financiar su actividad comercial, los socios de la firma Hijos de Fernando Restrepo \& Cía. optaron por el negocio bancario que adquiría cada vez mayor importancia. ${ }^{21}$

\section{Hijos de Fernando Restrepo \& Cía.: financiadores de los distritos municipales}

A pesar de que no fue posible conocer en detalle las condiciones financieras pactadas entre los señores Restrepo y los bancos en el exterior, se sabe que, al menos en los primeros años, estos obtuvieron cuantiosos recursos bajo la modalidad de créditos rotatorios. ${ }^{22}$ De acuerdo con los datos de la correspondencia comercial, la firma obtuvo préstamos, al menos hasta 1920, de las siguientes entidades: The Equitable Trust Co. (Nueva York), Anglo South American Bank (Londres), Commercial Bank of Spanish America (Londres), Mercantile Bank of the Americas Inc. (Nueva York) y Brown Brothers \& Co. (Nueva York). ${ }^{23}$

Hasta comienzos de la primera guerra mundial la casa comercial celebró contratos con el Anglo South American Bank y The Commercial Bank of Spanish America de Londres. Sin embargo, según lo explica Tovar (1984), con la primera guerra mundial se afirmaron nuevas condiciones internacionales para Colombia, destacando la preeminencia de Estados Unidos. En efecto, en 1916, en una carta dirigida a The Equitable Trust Co. (Nueva York) en la que solicitaban un crédito, los hijos de Fernando Restrepo explican que también tenían contratos con bancos americanos: "Actualmente lo tenemos con el Mercantile Bank of the Americas Inc. N. Y. y con los Señores Brown Brothers \& Co. N. Y., por \$25.000 dólares con cada Casa. Hasta hace pocos meses se hizo por $\$ 50.000$ con cada una hasta hace pocos meses cuando cambiamos el primer contrato por un préstamo directo con el Banco Mercantil Americano de Colombia, sociedad hija del Mercantil."24

17 Correspondencia comercial recibida de Fruhling \& Goschen, 3 de abril de 1885. Archivo Fernando Restrepo e Hijos (en adelante AFrH).

18 Notaría 1, núm. 1824, julio de 1899. AHA.

${ }^{19}$ Emilio Restrepo se desempeñaba como administrador de la Compañía de Tejidos de Bello.

${ }^{20}$ Carta a Schloss Brothers, marzo de 1911. AFRH.

${ }^{21}$ Carta a Comptoir National d'Escompte, febrero de 1912. AFRH.

22 Carta a Schloss Brothers, marzo de 1911. AFRH.

${ }^{23}$ No se dispone de información que permita verificar cuáles fueron las entidades bancarias que continuaron otorgándoles créditos en la década de 1920 para poder financiar a los distritos municipales.

${ }^{24}$ Carta a The Equitable Trust Company, abril de 1916. AFrH. 
Con el fin de garantizar dichos créditos, los señores Restrepo dieron en prenda las acciones que tenían en algunas de las compañías más importantes de la plaza de Medellín, tales como los de la Compañía de Tejidos de Medellín, El Banco de Sucre y la Compañía de Transportes. ${ }^{25}$

\section{Préstamos a los distritos municipales}

En medio de la transformación económica que experimentaba Antioquia, en particular en los distritos en donde se presentaba un auge de la producción de café, las autoridades locales buscaban iniciar proyectos que promovieran el progreso material: construcción de acueductos, trilladoras y mataderos, la instalación de plantas eléctricas, entre otros.

Adicional al riesgo del crédito, con un mercado de capitales que apenas comenzaba a organizarse, sin recursos propios suficientes para financiar los proyectos, uno de los problemas para las autoridades locales era encontrar fuentes de financiamiento. Aunque existían importantes entidades bancarias en Medellín, como el Banco de Sucre y el Banco Alemán Antioqueño, sus actividades eran principalmente comerciales, con préstamos a corto plazo, y cuyo objeto principal era financiar el activo y dinámico comercio externo e interno de dicha plaza comercial, así como el negocio cambiario, un negocio altamente especulativo que permitía obtener una elevada rentabilidad (Botero, 1994). Si bien, como menciona Avella (2004), "durante el auge crediticio banqueros de los Estados Unidos recorrieron Colombia en busca de oportunidades de inversión y los departamentos y municipios fueron un objetivo fácil” (p. 178), este no fue el caso para los municipios de Antioquia. Estos encontraron una fuente alternativa: los préstamos ofrecidos por una casa comercial-bancaria de Medellín que vio una oportunidad de invertir en nuevos proyectos. ${ }^{26}$

\section{Número total de préstamos otorgados}

A lo largo de 1912-1931 se concedieron 96 créditos a 45 distritos municipales. ${ }^{27}$ Lo anterior significa que cerca de la mitad de todos los municipios de Antioquia obtuvieron empréstitos por parte de los señores Restrepo (Contraloría General de la República, 1937). ${ }^{28}$

En la gráfica 1 se observa la evolución de los préstamos. Los primeros créditos se otorgaron al distrito de Fredonia, un importante y próspero municipio cafetero. ${ }^{29} \mathrm{~A}$ principios de la primera guerra mundial (1914-1915) se suspendieron los préstamos. No obstante, a partir de 1916 y hasta finales de 1920 se incrementó el número de créditos. En este periodo, se otorgó un total de 26 créditos por un valor de 261500 pesos oro.

25 Carta a The Equitable Trust Company, 1913. AFrH.

${ }^{26} \mathrm{Al}$ parecer, esta casa bancaria dominó el financiamiento de proyectos en los distritos municipales. Tiempo más tarde entró a participar una pequeña firma bancaria conocida como La Mutualidad Nacional.

${ }^{27}$ En este trabajo se estudiaron los 45 distritos que firmaron el acuerdo con la Sucesión en 1934. Betania, otro de los deudores, logró un acuerdo tiempo más tarde. Los distritos restantes, entre esos, Manizales, pertenecían todos al nuevo departamento de Caldas y no forman parte de este estudio.

${ }^{28}$ Según el censo de 1928 existían 98 distritos municipales en el Departamento de Antioquia, Colombia.

${ }^{29}$ Notaría 2, núm. 792, junio de 1912; núm. 97, enero de 1913. AHA. 


\section{GRÁFICA 1. NÚMERO DE PRÉSTAMOS OTORGADOS A LOS DISTRITOS MUNICIPALES DE ANTIOQUIA POR LOS SEÑORES RESTREPO, 1912-1931}

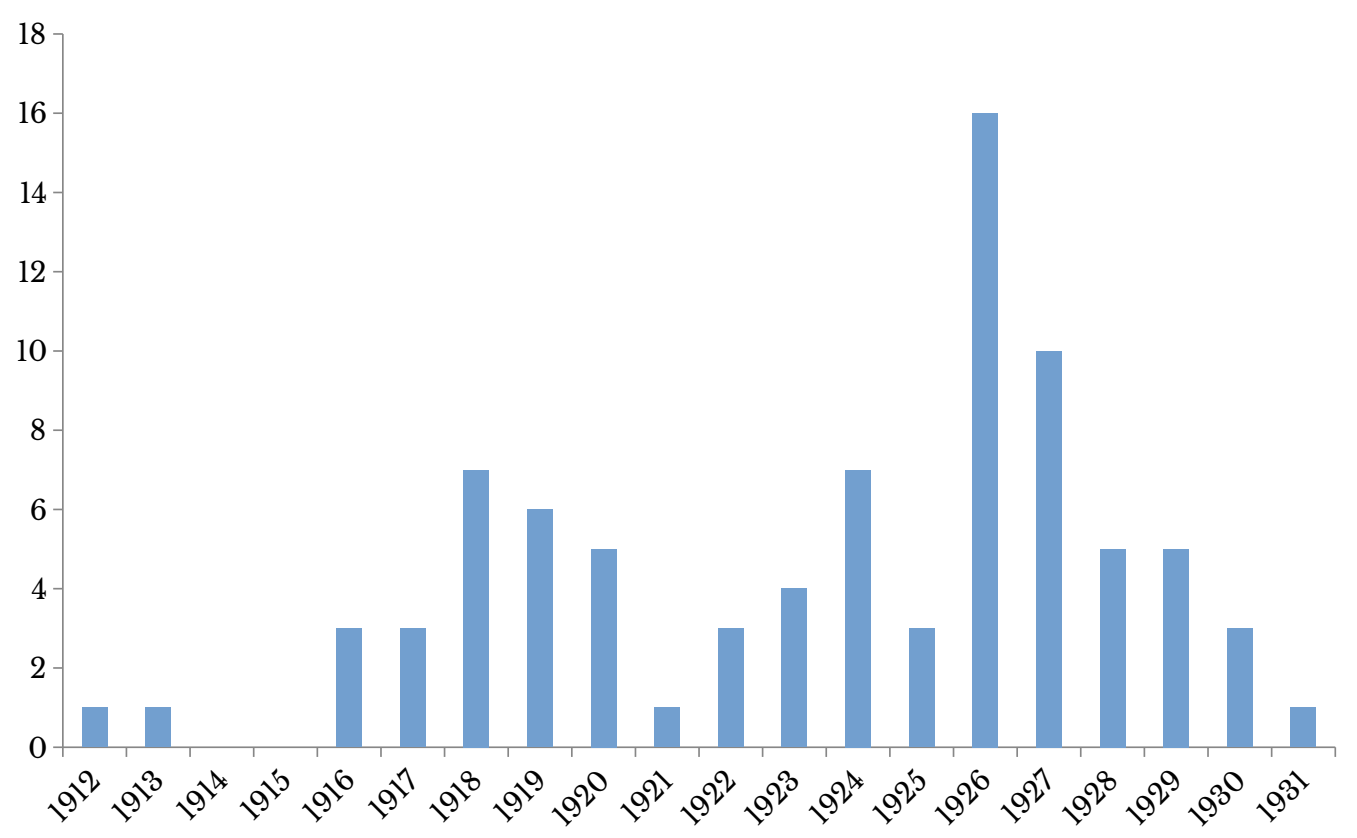

Fuente: elaboración propia con base en Artículo 6. Notaría 2. Escritura núm. 194, 27 de enero de 1934. AHA.

Esta expansión del crédito coincidió con un ciclo de crecimiento vigoroso de la economía de Antioquia: en estos años se crearon nuevas empresas fabriles en Medellín que producían, entre otros, calzado, telas, cerveza, cigarrillos, galletas y confites (Botero, 2003; Gaviria, 1923). ${ }^{30}$ Asimismo, las exportaciones del café aumentaron entre 1917 y 1920 cuando el país vivió una bonanza exportadora inducida por el aumento en la cotización internacional del grano. A finales de 1918, los precios del café en Nueva York tuvieron un incremento de $71 \%$ como consecuencia de dos fenómenos simultáneos: la restricción de la oferta por una helada en Brasil y la reapertura de la demanda europea al término de la guerra. El precio del café se mantuvo alto durante 1919 (Palacio, 1979), un año de gran prosperidad en Antioquia, como bien comentó el general Pedro Nel Ospina al ministro de Gobierno en su momento: "Creo que nunca en la historia de Antioquia se había presentado una época de mayor y más visible prosperidad material” (Ospina, 1927).

De 1920 a 1922 el número de empréstitos otorgados a los distritos municipales se redujo. En 1921 sólo se aprobó un empréstito, y tres más en 1922. Lo anterior guarda relación con la crisis del sector externo y las dificultades financieras que se presentaron a comienzos de la década de 1920 cuando los precios internacionales del café comenzaron a descender. Ante la difícil situación del mercado del café en Nueva York, varias casas comisionistas abiertas por antioqueños en Nueva York que habían contraído créditos por sumas elevadas no pudieron cumplir con sus compromisos

${ }^{30}$ En 1923 se habían establecido en el municipio de Medellín seis fábricas de tejidos, cinco de cigarrillos, tres de fósforos, once trilladoras de café, 20 ingenios de azúcar y panela, cuatro fundiciones de oro y plata, ocho fábricas de velas y jabones, dos de cerveza, seis de chocolate, fábricas de confites y galletas, entre otras (Gaviria, 1923). 
y suspendieron los pagos. Dado los estrechos vínculos que existían entre las firmas exportadoras y el Banco de Sucre, dicha entidad bancaria entró en una grave crisis, lo que condujo a su posterior liquidación (Botero, 1994). Adicionalmente, en 1921 tuvo lugar la disolución de la casa comercial Hijos de Fernando Restrepo \& Cía. ${ }^{31}$ A partir de 1922, el señor Restrepo reanudó la financiación a los distritos.

En la década de 1920 Antioquia experimentó una época de prosperidad. Asimismo, Colombia tuvo un crecimiento rápido como resultado de la mejoría del sector externo y de las divisas provenientes por el pago que hizo Estados Unidos por concepto de la indemnización de Panamá. La tasa de crecimiento del producto interno bruto (PIB) alcanzó 9.6 \% en 1926 y 9 \% en 1927 (Sánchez, 1994, p. 85).

Fue precisamente en estos años de auge e intensa especulación financiera -en el periodo prosperidad al debe- cuando el señor Restrepo incrementó excesivamente la cantidad de préstamos, alcanzando el punto máximo en 1926, según se observa en la gráfica 1. Tan sólo en este año otorgó 16 empréstitos por un valor cercano a 408000 pesos oro, lo que equivale a $34 \%$ del valor total de todos los recursos desembolsados a los distritos. En 1927, doce municipios recibieron préstamos por un valor de 221000 pesos oro colombiano.

$\mathrm{Al}$ parecer, en estos años se produjo un giro en relación con la asignación de los créditos. Todo indica que al menos hasta 1920 la casa comercial de los señores Restrepo había optado por financiar a importantes distritos cafeteros que seguramente contaban con rentas más elevadas dada su actividad económica. Asimismo, las sumas desembolsadas no sobrepasaban los 10000 pesos, salvo un préstamo desembolsado a Fredonia por 25000 pesos y uno por 30000 a Concordia. Sin embargo, en los años 1926 y 1927 se otorgaron préstamos a numerosos y pequeños distritos municipales, algunos con una precaria actividad económica. ${ }^{32}$ Además, no sólo se incrementó el número de préstamos, sino también su valor. En suma, el señor Restrepo otorgó por primera vez recursos por un valor de 50000 pesos oro a cinco distritos.

La adjudicación de empréstitos comenzó a decrecer en 1928: se adjudicaron cinco ese año, tres en 1930 y uno en 1931. Las dificultades ya habían comenzado a sentirse y la crisis económica causada por la Gran Depresión golpeaba a Colombia. Los nuevos flujos de capital se habían estancado. No se conoce la forma en que el señor Restrepo renegoció sus deudas, las obligaciones con sus acreedores y la capacidad de honrar los compromisos contraídos. No obstante, es correcto afirmar que su situación financiera debió verse afectada una vez que se estancaron los créditos a raíz de la crisis de 1930 .

${ }^{31}$ Notaría 2. Escritura núm. 719, 15 de mayo de 1921. AHA.

${ }^{32}$ A partir de mediados de la década de 1920 obtuvieron créditos varios distritos municipales que anteriormente no habían obtenido financiación. Muchos dependían de una precaria economía local. Véanse las monografías de Antioquia, las cuales comenzaron a aparecer en 1922 bajo la dirección de José Gaviria “con el fin de impulsar la reactivación del desastre económico de los años de 1920 y 1921 ”. Los tomos 1 y 2 abarcaban los municipios de Caldas, Fredonia, Abejorral y Amalfi (Colombia, 1922). En 1941, la empresa Cervecería Unión decidió recopilar aquellos estudios en un volumen. En 1978 fueron reeditadas bajo la dirección de Heriberto Zapata por la Cervecería Unión. 


\section{GRÁFICA 2. VALOR ANUAL DE LOS PRÉSTAMOS OTORGADOS A LOS DISTRITOS MUNICIPALES DE ANTIOQUIA POR LOS SEÑORES RESTREPO, 1912-1931}

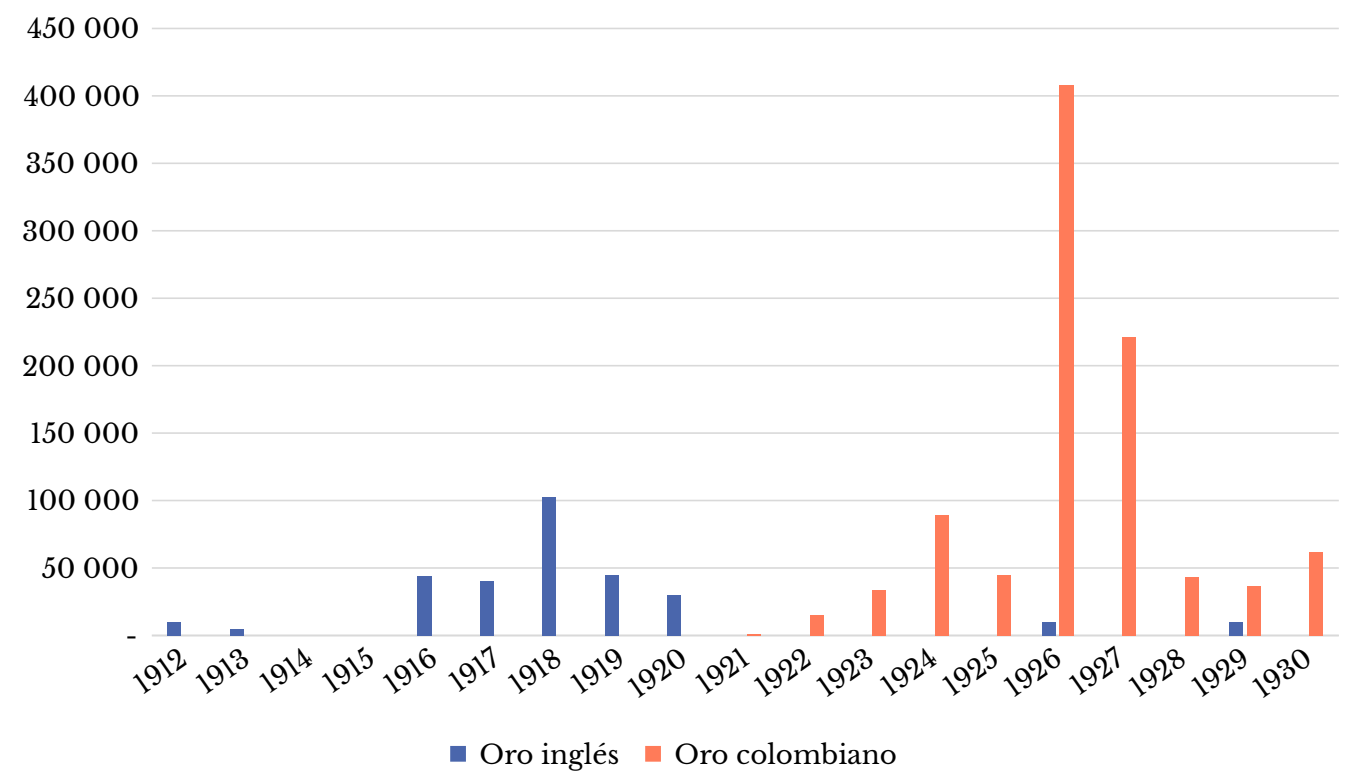

Fuente: Artículo 10. Notaría 2, Escritura núm. 194, 27 de enero de 1934. AHA.

\section{Valor de los préstamos}

En la gráfica 2 puede observarse el valor anual de los préstamos otorgados a los distritos municipales. De 1912 a 1920 los préstamos se pactaron en oro inglés amonedado o su equivalente; ${ }^{33}$ a partir de 1921 se hicieron en oro colombiano amonedado. ${ }^{34}$

La deuda de los distritos municipales al momento de realizarse el arreglo ascendía a 1196261 pesos oro, y el valor de las rentas de todos sumaban 268469 pesos oro Así, en conjunto, los distritos estaban endeudados en 4.5 veces sus rentas (véase gráfica 3 ).

${ }^{33}$ Ley 35. Sobre régimen monetario. Diario Oficial, 24 de junio de 1907. Dicha Ley estableció como patrón monetario el peso fuerte de oro, equivalente a la quinta parte de la libra esterlina inglesa tanto en peso como en ley. El artículo 9 señalaba la vigencia de la libre estipulación de monedas nacionales y extranjeras y en consecuencia toda obligación contraída, pagadera en determinada clase de moneda, debería cumplirse en la moneda estipulada o su equivalente en monedas legales de la nación al tipo comercial que tuviese el día del pago en el respectivo mercado.

${ }^{34}$ En 1934 las deudas de todos los distritos quedaron convertidas a oro colombiano amonedado (o su equivalente). 


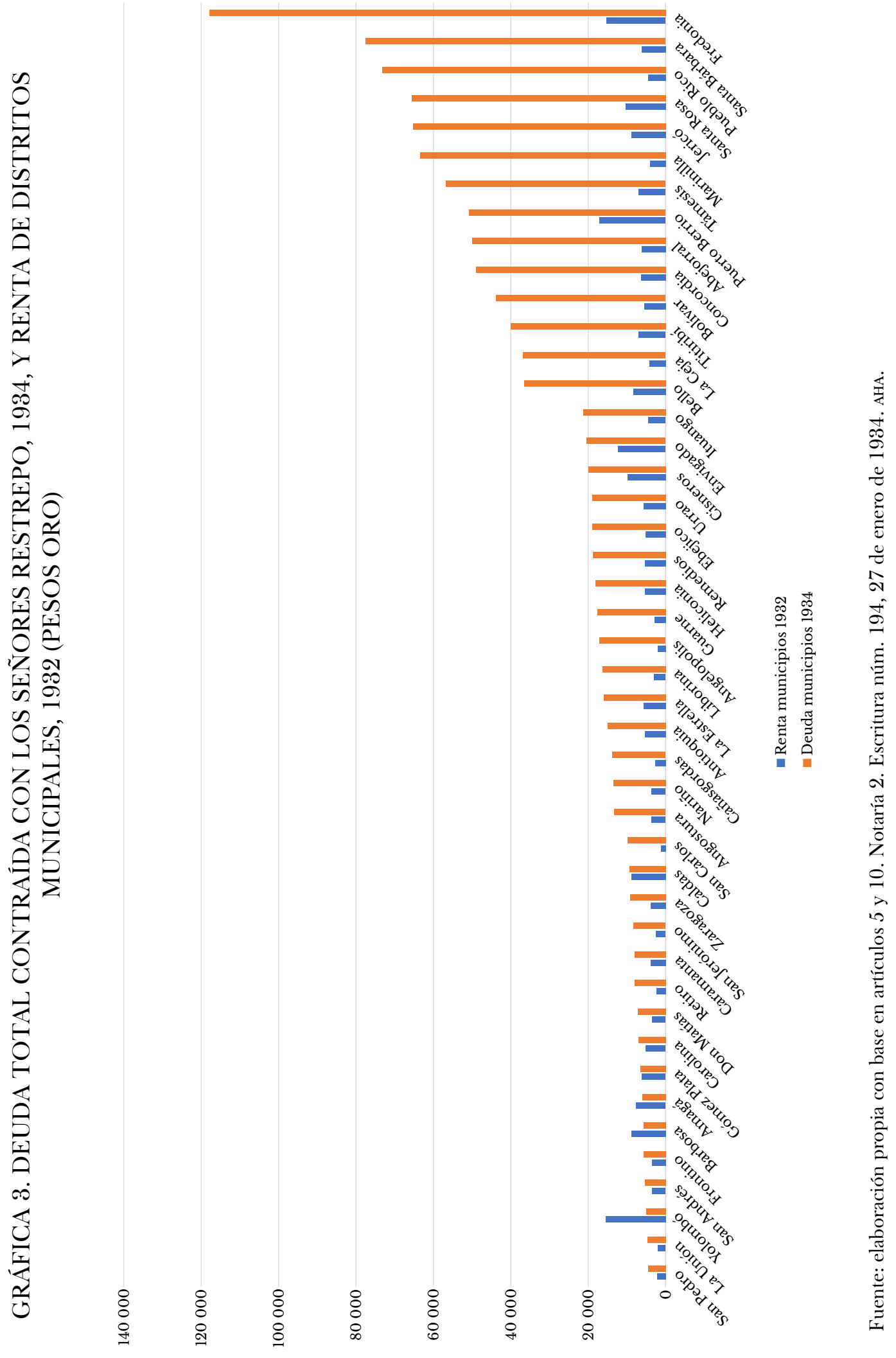


Según se observa en el apéndice 1, en sólo tres distritos sus ingresos superaban el valor de la deuda contraída con el señor Restrepo. En 25 distritos municipales la deuda era menor a cinco veces sus rentas. Por su parte, en catorce más la deuda se encontraba entre cinco y diez veces sus rentas. En este rango se encontraban varios distritos municipales que tenían menos de 7000 habitantes en 1928 y con rentas exiguas. Un caso notable es el de Angelópolis, un municipio de tan sólo 5000 habitantes, con una renta de 2027 pesos, que se hallaba endeudado con 17072 pesos oro. Pero sin duda los casos extremos fueron Pueblo Rico y Marinilla con una deuda de 16 y 15.66 veces sus rentas.

El monto de los préstamos varió: 51 \% se otorgó por sumas menores de 10000 pesos oro, donde el de menor valor fue por 2000 pesos oro que se entregó a tres distritos diferentes con el fin de terminar la instalación de plantas eléctricas. Otras sumas elevadas de dinero (50 000 pesos oro) fueron otorgadas en 1926 y 1927 a cinco distritos: a Puerto Berrío para la construcción de un nuevo acueducto; a Santa Bárbara para el pago de un préstamo que se le adeudaba a La Mutualidad Nacional; a Támesis para la construcción de un acueducto y la terminación de la cárcel; a Bolívar con el fin de construir un acueducto de hierro y ampliar la Casa Consistorial y a Santa Rosa para el pago a la firma bancaria La Mutualidad Nacional de dos créditos obtenidos para la construcción del acueducto, mejora y ensanche de la planta eléctrica y obras de la carretera roncal del Norte. ${ }^{35}$

Diez distritos municipales obtuvieron el mayor número de préstamos, representando $55.96 \%$ del total de todos los créditos desembolsados (véase gráfica 4). Estos fueron Abejorral, Concordia, Jericó, Marinilla, Puerto Berrio, Santa Rosa, Santa Bárbara, Támesis, Pueblo Rico y Fredonia. Este último ocupaba el primer lugar en volumen de producción de café (Censo Cafetero, 1932). Fredonia obtuvo de los señores Restrepo nueve préstamos por un valor de 117861 pesos oro y su participación en el valor total de los créditos otorgados fue de 9.85 \% (véase gráfica 4). Todos estos distritos, con excepción de Marinilla, Puerto Berrio y Santa Rosa, eran importantes productores de café en Antioquia (Censo Cafetero, 1932).

\section{Uso y destino de los préstamos}

La instalación de plantas eléctricas constituyó el proyecto prioritario en estos años. El 34.88 \% de los préstamos se destinó a atender asuntos relacionados con la energía eléctrica, bien fuese para la construcción de una planta eléctrica, su terminación, reparación o ensanche (véase gráfica 5). Como parte del progreso técnico se demandaba electricidad para la instalación o mejoramiento del alumbrado público. Además, en municipios cafeteros como Fredonia, Pueblo Rico y Concordia se instalaron trilladoras, lo que implicó avances en la economía cafetera.

En 1916 el municipio de Concordia declaró de utilidad pública la instalación de la luz y autorizó un empréstito de 15000 pesos: préstamo que otorgó la casa Hijos de Fernando Restrepo \& Cía. de Medellín. Como el empréstito resultó insuficiente la misma casa otorgó uno nuevo por 5000 pesos, pues además de la planta se construyó una trilladora de café. La planta de 60 kilovatios tuvo, junto con la trilladora, un costo aproximado de 28875 pesos (Zapata, 1978).

Las obras del acueducto público ocuparon el segundo lugar en la prioridad de las administraciones locales. Se pidieron préstamos para la construcción de acueductos públicos, o su reforma, y, en uno de los casos, para la terminación de un acueducto con tubería de hierro. También los distritos solicitaron préstamos para la construcción, ensanche y mejora de mataderos públicos.

${ }^{35}$ Notaría 2. Escrituras núm. 2115, 3 de julio de 1926; núm. 2747, 24 de agosto de 1926; núm. 1085, 24 de marzo de 1927; núm. 3338, 20 de agosto de 1927; núm. 4373, 18 de agosto de 1927. AHA. 


\section{GRÁFICA 4. PARTICIPACIÓN DE LOS DISTRITOS EN EL TOTAL DE LOS CRÉDITOS OTORGADOS POR LOS SEÑORES RESTREPO}
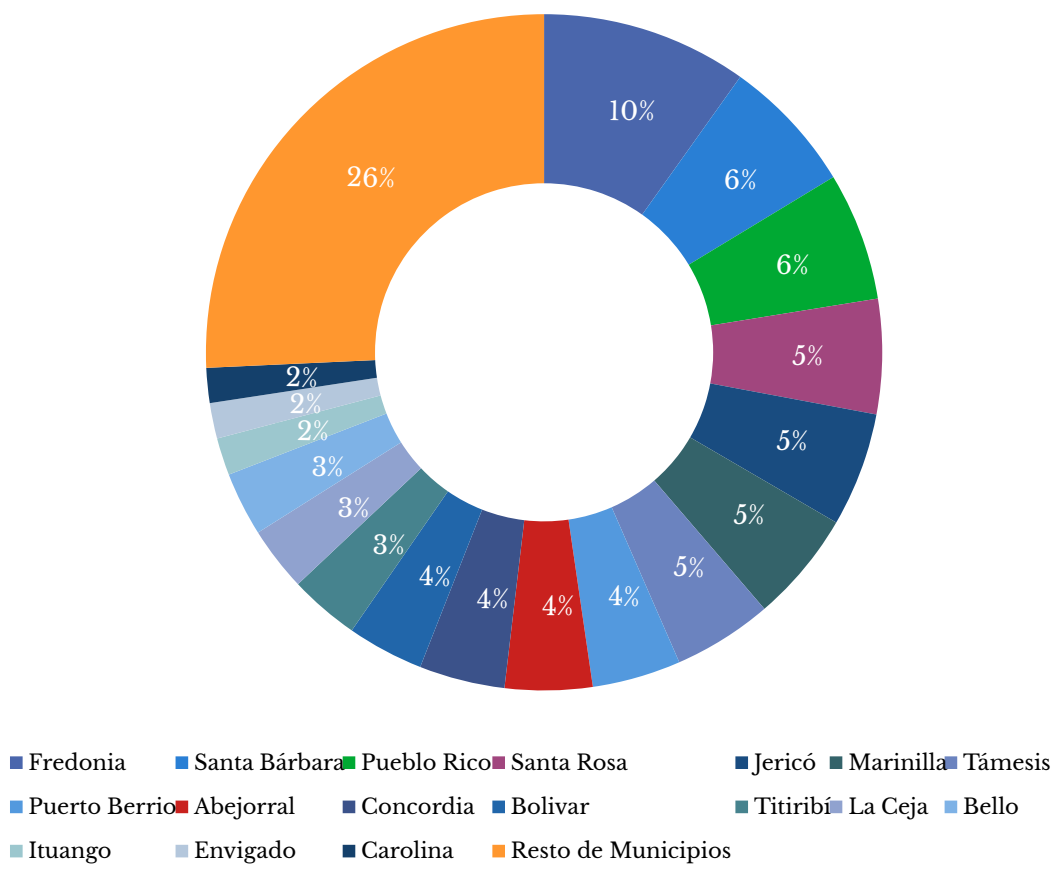

Fuente: elaboración propia con base en datos de las 96 escrituras públicas por préstamos otorgados.

En algunos casos, las autoridades locales solicitaron recursos para la terminación de algunos proyectos. Remedios, a manera de ilustración, solicitó cuatro préstamos en el periodo entre 1926 y 1929 para terminar la construcción de su planta eléctrica. Asimismo, el municipio de Fredonia obtuvo cuatro préstamos para la terminación del acueducto municipal entre 1918 y 1919. Por último, cabe mencionar los empréstitos que tuvieron como finalidad refinanciar deudas. Un $11.63 \%$ de estos se destinaron al refinanciamiento de deudas contraídas anteriormente con el señor Restrepo o con la casa bancaria La Mutualidad Nacional de Medellín.

No se sabe quién dirigía y supervisaba las obras. Tampoco es claro si existía un control sobre el uso de los recursos y si se vigilaba que estos cumplieran el fin para el cual había sido otorgado el crédito. No obstante, existe información acerca de la participación de firmas de ingenieros de Medellín. Juan J. Ángel fue el encargado de realizar los estudios para el montaje de la planta eléctrica de Concordia; un ingeniero francés, Francisco Navache, planeó y dirigió la obra del acueducto de Fredonia; Cock, Sanín \& Cía. dirigió el acueducto metálico en Jericó y Ángel Osorio participó en el montaje de plantas eléctricas, entre ellas la de Pueblo Rico (Zapata, 1978).

Para la instalación de plantas eléctricas se importó maquinaria por medio de representantes de firmas extranjeras. En 1928 se autorizó en Puerto Berrío un empréstito por hasta 70000 pesos oro, destinados exclusivamente al montaje de una planta eléctrica no menor a 200 kilovatios. El personero del municipio firmó un contrato con Greiffenstein, Angel \& Co., representantes de Schulibach, Thiemer \& Co. (Hamburgo), para que dicha firma despachara la maquinaria cuya par- 


\section{GRÁFICA 5. PARTICIPACIÓN DEL USO Y DESTINO DE LOS PRÉSTAMOS OTORGADOS POR LOS SEÑORES RESTREPO, 1912-1934}

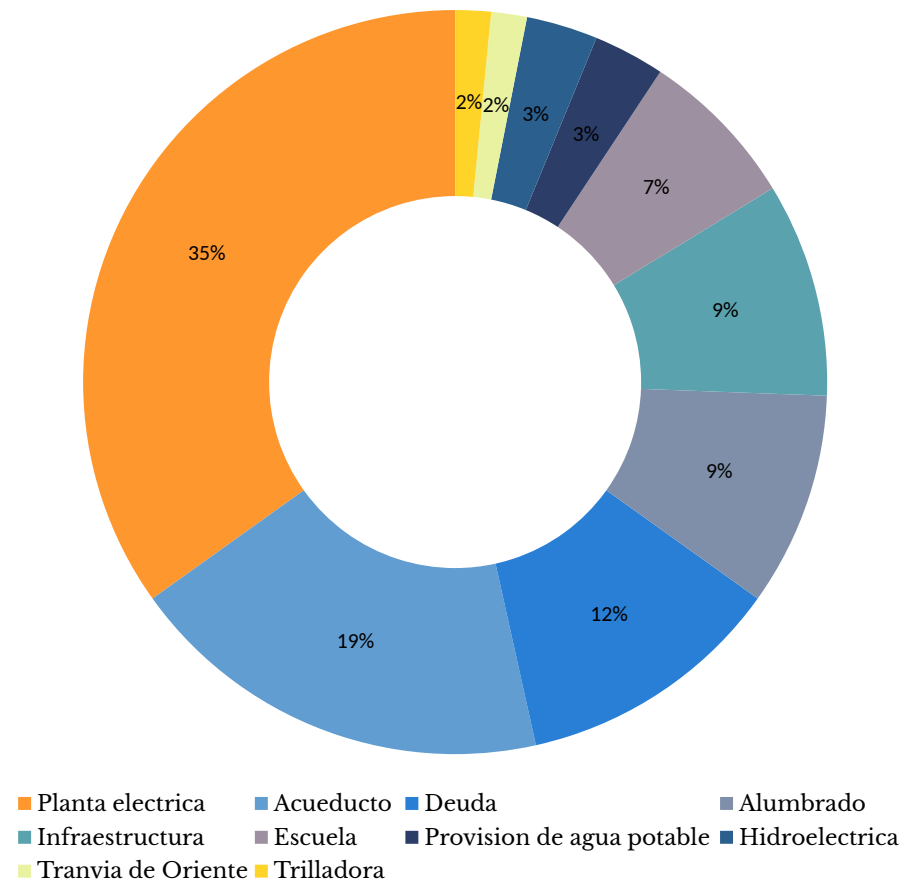

Fuente: elaboración propia con base en datos de las 96 escrituras públicas referentes a préstamos otorgados.

te eléctrica sería de la marca Siemens y el resto de conocidas fábricas alemanas (Zapata, 1978). La maquinaria importada de Estados Unidos provenía de la firma Westinghouse Electric Manufacturing \& Co. (Nueva York), que apenas ingresaba al mercado nacional y se adquiría por intermedio del ingeniero eléctrico Martín del Corral, quien aparecía en la lista de los distribuidores exclusivos de esta firma estadunidense (Westinghouse Electric \& Manufacturing Company, 1924). ${ }^{36}$ En 1916 se creó en Marinilla la Junta de Alumbrado Eléctrico y se firmó un contrato con Cock, Sanín \& Cía. para que se encargara de dirigir el montaje, enseñar su funcionamiento, y pedir la maquinaria a la Westinghouse Electric \& Manufacturing Co. ${ }^{37}$

\section{Política de adjudicación y desembolso de los créditos}

La consecución de un empréstito por parte de un concejo municipal estaba sujeta a las normas de carácter nacional y a las ordenanzas departamentales. A partir de la Ley 20 de 1908 se les permitió a los municipios una mayor libertad para invertir y administrar las rentas y se les delegó con

${ }^{36}$ En esos años este era el distribuidor para Colombia y su oficina Martin del Corral \& Cía. estaba localizada en Nueva York. Años más tarde ocuparía la presidencia del Banco de Bogotá.

${ }^{37}$ La maquinaria para el montaje de una planta eléctrica en Santa Rosa también fue suministrada por la Westinghouse Electric \& Manufacturing Co. 
aprobación del gobierno nacional y departamental la contratación de empréstitos con entidades públicas y privadas dentro y fuera del país. ${ }^{38}$ Estos empréstitos debían ser exclusivos para mejoras materiales de urgente necesidad pública. ${ }^{39}$

No es del todo claro cómo se establecieron las relaciones entre las autoridades locales y la casa prestamista y si el crédito lo solicitaba directamente el concejo municipal o participaban e intervenían intermediarios y comisionistas. Sin embargo, es probable que políticos y personajes importantes que tenían intereses económicos en un determinado municipio intervinieran en la consecución de estos préstamos. Así, por ejemplo, la familia Ospina tenía haciendas cafeteras en Fredonia. ${ }^{40}$ El mismo gobernador de Antioquia, Julián Uribe, quien logró el arreglo entre la sucesión y los distritos, poseía cultivos en dicho municipio.

Por otro lado, se sabe que el concejo de cada municipio era el encargado de estudiar la propuesta y, en caso de ser aprobada, entregar un poder al personero municipal, quien era el encargado de hacer las negociaciones y de presentar nuevamente los términos del crédito. Cuando el concejo en pleno lo aprobaba se le enviaba al gobernador para su estudio y aprobación. Una vez aprobada se remitía a la asamblea departamental para que se hiciera un proyecto de ordenanza. Por último, se remitía al Ministerio de Gobierno. Una vez autorizado y con el fin de legalizar el contrato se elevaba a escritura pública. A partir de entonces, la casa comercial procedía a abrir una cuenta corriente a nombre del respectivo concejo municipal por el valor del préstamo. Por tanto, cada distrito al cual se le había otorgado un empréstito tenía en la contabilidad de la firma comercial una cuenta donde figuraban los giros que hacía tanto para retirar sumas de dinero como para abonarlas.

\section{Condiciones pactadas entre los distritos y el acreedor}

Los préstamos fueron de largo plazo, generalmente a quince años. En garantía de sus obligaciones, los distritos comprometieron a favor de los señores Restrepo una serie de bienes y rentas. Según puede observarse en las 96 escrituras, los distritos otorgaron hipotecas sobre propiedades públicas de los municipios, tales como el matadero público, la planta de energía, la Casa Consistorial, los edificios de la cárcel y escuelas, y otros lotes, más un porcentaje sobre las rentas departamentales y la totalidad de las rentas municipales. ${ }^{41}$

La tasa de interés efectiva anual fijada por los prestamistas de 1912 a 1930 no eran diferenciales, excepto en una ocasión en que se le otorgó un préstamo a Fredonia con una tasa de interés anual fija a $15 \%$, mientras el mismo año se fijó $16 \%$ para otros tres municipios. De 1916 a 1925 se mantuvo inalterada la tasa de interés en $16 \%$ efectiva anual (véase gráfica 6 ). A partir de junio de 1925, el señor Restrepo modificó la tasa a $12 \%$ anual. Este descenso obedeció quizá a la creciente entrada de capitales, no sólo por la mejora en las exportaciones del país, sino también por la adición de divisas provenientes de la indemnización de Panamá por un valor de 25000000 de dólares (Bejarano, 1997). De esta manera, la tasa de interés fijada por el señor Restrepo permane-

${ }^{38}$ Ley 20 de 1908. Que adiciona y reforma la Ley 149 de 1888, sobre régimen político y municipal, Diario Oficial, 3 de septiembre de 1908.

${ }^{39}$ A partir de 1928 el gobierno estuvo en capacidad de objetar la contratación de un empréstito con base en el artículo 8, Ley 6, Sobre empréstitos.

${ }^{40}$ El general Pedro Nel Ospina fue diputado por el distrito de Fredonia (Asamblea de Antioquia, 1917, 1918).

${ }^{41}$ Artículo 4. Notaría 2, Escritura núm. 194, 27 de enero de 1934. AHA. En este documento aparecen los bienes dados en garantía por los distritos municipales. 


\section{GRÁFICA 6. TASA DE INTERÉS EFECTIVO ANUAL DE LOS PRÉSTAMOS OTORGADOS A LOS DISTRITOS MUNICIAPLES POR LOS SEÑORES RESTREPO} (1912-1930)

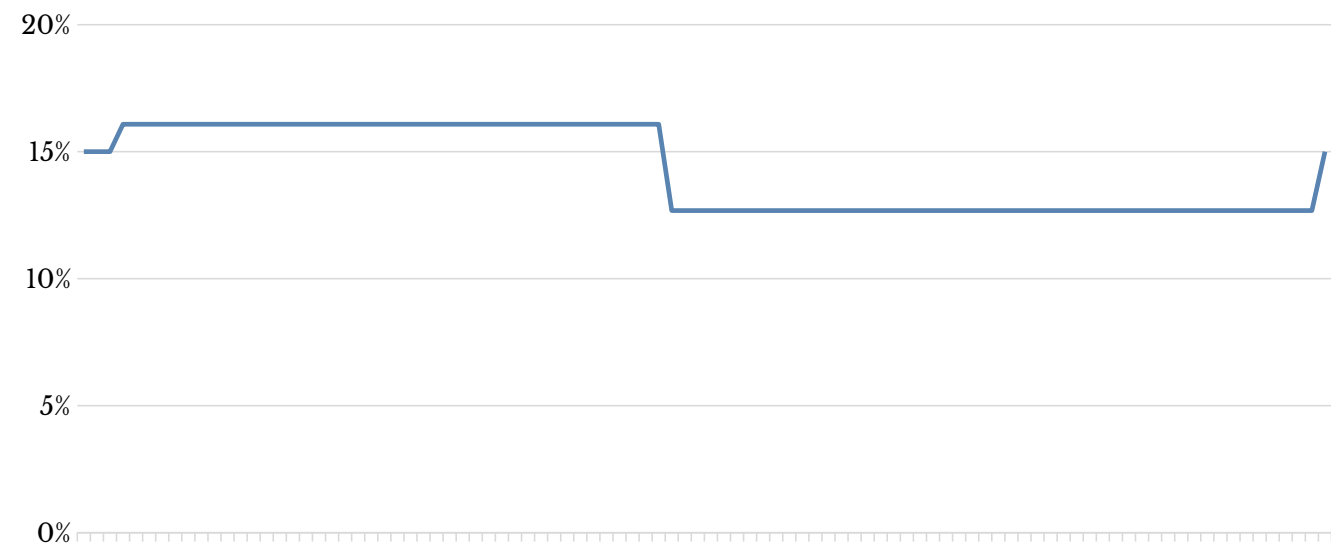

Fuente: elaboración propia con base en datos de las 96 escrituras públicas por préstamos otorgados.

ció sin modificaciones hasta 1930. En 1931 otorgó el último empréstito que tuvo como finalidad refinanciar los préstamos desembolsados desde 1912 al distrito municipal de Fredonia. En esta ocasión fijó la tasa de interés en $15 \%$ anual.

Cabe preguntarse ahora qué tan representativa eran estas tasas respecto a las tasas de interés que cobraban los bancos de Medellín o de otras plazas comerciales como Bogotá. En Medellín el Banco Alemán Antioqueño cobraba en la década de 1910 alrededor de 13 y $14 \%$ efectivo anual. ${ }^{42}$ Sólo en momentos de dificultades monetarias, como ocurrió a finales de 1913, posteriormente en 1917 y en noviembre de 1920, tanto el Banco de Sucre como el Banco Alemán Antioqueño incrementaron la tasa a $15 \%$ anual (Botero, 2012). En su momento, las tasas de interés en la Banca Bogotana se situaron en $12 \%$ anual entre 1912 y 1922 (Romero, 1994, p. 297, cuadro 6.8).

Si bien la reducción de la tasa de interés que se aplicó a todos los préstamos otorgados a partir de 1925 redujo el costo del financiamiento, este continuaba siendo muy elevado. El gobierno nacional así lo consideraba, absteniéndose de autorizar en 1927 el empréstito que solicitaba el municipio de Santa Rosa a la firma Emilio \& Lázaro Restrepo \& Cía. Dicho distrito municipal solicitó recursos por un valor de 50000 pesos oro, a quince años con una tasa de interés de $12 \%$ anual, con el fin de cancelarle a la firma bancaria La Mutualidad Nacional dos créditos obtenidos para la construcción del acueducto. El gobierno nacional consideró que la tasa estipulada no sólo era muy elevada, sino que las municipalidades debían procurar aprovechar las condiciones favorables que se observaban entonces en el mercado de capitales. ${ }^{43}$

${ }^{42}$ Esta información fue consultada en el Libro de Actas de la Junta Directiva 1913-1923 del Banco Alemán Antioqueño. Este banco cambió su nombre durante la segunda guerra mundial por el del Banco Comercial Antioqueño.

${ }^{43}$ Empréstito de Emilio y Lázaro Restrepo al municipio de Santa Rosa. Notaría 2, Escritura núm. 3338, 20 de agosto de 1927. AHA. 
No obstante, y a pesar de las condiciones onerosas, el presidente del Concejo Municipal de Santa Rosa solicitó que se reconsiderase la mencionada resolución ya que en su opinión no era posible obtener préstamos con tasas más favorables. Para ello, alegó:

Sin dejar de considerar que son loables bajo todo punto de vista las buenas intenciones del Ejecutivo, al procurar porque las entidades municipales consigan los empréstitos para sus obras públicas a interés módico, debo manifestar a Vuestra Señoría que a este negocio de dar dinero a interés a los Distritos no se dedican en Medellín sino los prestamistas señores Restrepo y La Mutualidad Nacional, condiciones las de esta última entidad que son más onerosas todavía. ${ }^{44}$

Concluyó solicitando que se reconsiderara dicha resolución y se autorizara al municipio para contratar el empréstito en los términos convenidos con la casa prestamista, con el fin de concluir las obras ya empezadas.

$\mathrm{Al}$ parecer, ante solicitudes similares, la gobernación argumentó que, si bien era cierto que el mercado de Bogotá ofrecía tasas inferiores en dos puntos, o sea, a $10 \%$, esa diferencia quedaría compensada y superada por los gastos de comisión y otros varios que implicaría la consecución de empréstitos en los bancos de la capital. Fue sólo a raíz de la reestructuración en 1934 cuando se logró pactar entre los distritos y el acreedor una tasa de $6 \%$ anual.

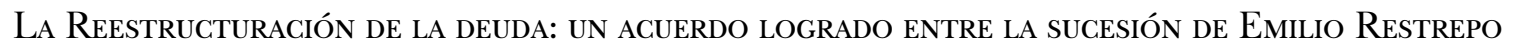 Y ALGUNOS DISTRITOS MUNICIPALES}

La década de 1930 se inició en el campo político con la república liberal después de largos años de hegemonía conservadora. Coincidió también con el impacto de la Gran Depresión de 1929 sobre la economía colombiana. Al respecto, Ocampo (1997) menciona: "esos primeros años de la gran depresión estuvieron dominados en Colombia por el colapso del mercado del café y por la brusca interrupción de los flujos de capital" (p. 282). El cierre del crédito externo y el descenso de las exportaciones e importaciones implicó un fuerte impacto de la crisis mundial en el Estado colombiano (véase Tovar, 1984, p. 190).

Efectivamente, a comienzos de 1930, el gobernador explicó con alarma la situación fiscal en que se encontraba el departamento de Antioquia, por la que se había visto obligado a tomar medidas drásticas para recortar el gasto público (Mensajes del gobernador a la Asamblea, 1930, p. 268). Para el gobernador, el origen de la fuerte deuda había sido la necesidad de atender con eficacia y prontitud las obras públicas: "ya no [era] tiempo de discutir sobre la bondad de las inversiones sino de recaudar con celo los dineros y de pagarlos centavo por centavo, escrupulosa y oportunamente". Además, siguiendo su explicación, la mayor parte de las rentas del departamento estaban comprometidas con los prestamistas extranjeros y sus productos habían de depositarse a medida que se recaudasen, por ciertos periodos, en manos de quienes representaban a los banqueros.

Adicionalmente, el gobierno nacional adeudaba al departamento una suma elevada por diversos conceptos, entre otros, por menor producto de la renta de licores. Por ello, ante el déficit abrumador del departamento, las autoridades no lograban transferir el pago completo de lo que se adeudaba a los distritos municipales.

${ }^{44}$ Empréstito de Emilio y Lázaro Restrepo al municipio de Santa Rosa. Notaría 2, Escritura núm. 3338, 20 de agosto de 1927. AHA. 
La situación fiscal de los distritos a su vez se había venido agravando y sus rentas experimentaban un descenso constante. En 1931, las administraciones locales manifestaron su preocupación y descontento. En una carta a la asamblea departamental, el presidente del concejo del distrito municipal de Titiribí solicitó el pago de la participación en las rentas departamentales que le correspondían al municipio por un valor de 5 233, argumentando que su situación fiscal era muy grave. Además, anotaba que los distritos municipales debían atender no sólo los pagos más urgentes del municipio, sino también sumas considerables por intereses sobre créditos obtenidos tiempo atrás (Asamblea de Antioquia, 1931).

Por esta época se comenzó a pedir la moratoria y se cuestionaba la conveniencia de mantener el servicio de la deuda ya que existían necesidades internas apremiantes. En El Diario, un periódico liberal de Medellín, se pedía la moratoria. ${ }^{45}$ Otro tanto ocurría en diversas partes del país. Así, por ejemplo, en febrero de 1932 el Concejo de Manizales estudió el asunto de la moratoria y, un mes más tarde, la Asamblea del Valle declaró en primer debate una ordenanza declarando la moratoria. También en estos meses tanto el Concejo de Bogotá como la Asamblea de Cundinamarca discutían la suspensión de pagos de la deuda externa. ${ }^{46}$

En marzo de 1932 en sesiones secretas, la Asamblea de Antioquia aprobó la proposición sobre moratoria del servicio de la deuda externa. De acuerdo con el informe que presentó una comisión a los diputados, los efectos de la moratoria no salvarían la situación fiscal y económica del departamento, pero creían que los trastornos de esa medida serían menores a los que traería cualquier otra solución, pues se evitaría la dolorosa labor de rebajar sueldos y suprimir empleos (Asamblea de Antioquia, 1932). Al suspenderse el servicio de la deuda externa, el gobierno nacional suspendió también el suministro mensual de fondos (Memorias del ministro de Hacienda, 1931, 1932). El departamento de Antioquia había entrado en moratoria y el gobierno nacional había suspendido el envío de fondos.

Esta era la crítica situación al momento del fallecimiento del señor Emilio Restrepo. Por ello, los herederos, así como los albaceas de la sucesión, acudieron ante el gobierno nacional y a la Asamblea de Antioquia con el fin de iniciar gestiones para llegar a un acuerdo entre los municipios deudores y los acreedores ${ }^{47}$ (Gaceta Departamental de Antioquia, 1934, núm. 4179).

En junio de 1933, bajo la presidencia del doctor Francisco Rodríguez Moya, quien en ese entonces se desempeñaba como secretario de Hacienda del Departamento, y actuando como designado especial de la gobernación, se reunió una asamblea de delegados de los municipios deudores de don Emilio Restrepo. Ante esta, el doctor Rodríguez Moya hizo una exposición completa de un plan de arreglo de las deudas proyectado con la sucesión. Esa exposición tuvo como resultado el nombramiento de una comisión de cinco delegados de esa asamblea que deberían entenderse con los albaceas sobre la manera en que podría llevarse la liquidación de intereses pendientes y otros puntos que habían surgido en el debate.

Finalmente, como resultado de las deliberaciones, fue aprobada por unanimidad una proposición mediante la cual se apoyaba el proyecto celebrado con la gobernación del departamento y los acreedores de los municipios, siempre y cuando estos redujeran los intereses pendientes de las deudas al tipo de 6 \% anual (Memorias del secretario de Hacienda del Departamento de Antioquia, 1934).

45 "La moratoria se impone", El Diario, enero de 1932.

${ }^{46}$ Véanse, "Manizales decretará la moratoria”, El Diario, febrero de 1932; "Asamblea liberal del Valle debate la moratoria, El Diario, marzo de 1932, y”Cundinamarca decretará la moratoria, El Diario, marzo de 1932.

${ }^{47}$ A su turno el gobierno nacional estaba hondamente preocupado por los desastrosos efectos que en la economía del país estaba causando el grave problema de las deudas de carácter privado. Véase Jaramillo (1932). 
El arreglo se concretó en 1934 tras una negociación larga y difícil que fue, según el gobernador de Antioquia, "uno de los asuntos más serios que tuvo resolver la administración gubernamental de Antioquia a comienzos de los años treinta" (Gaceta Departamental de Antioquia, 1934, núm. 4179).

El acuerdo quedó plasmado en una escritura pública y fue firmado por el gobernador de Antioquia, el superintendente de Rentas del Departamento, el representante del Banco Central Hipotecario, la viuda del señor Restrepo y sus hijos, los albaceas de la sucesión y los representantes de los distritos municipales. ${ }^{48}$

Como parte del acuerdo, el departamento se obligó a retener, mes por mes, las cantidades necesarias para atender al puntual servicio de la deuda de las participaciones en las rentas departamentales, así como a comprometer su propia responsabilidad para reforzar las obligaciones de los distritos. Todas las deudas distritales quedaron convertidas en una sola deuda pública merced a la emisión de títulos o pagarés en la especie de bonos al portador contra las entidades deudoras y a favor de la sucesión; deudas públicas que, cuando fue necesario, el departamento respaldó con sus propios fondos, buscando cumplir con el pago oportuno y completo de la deuda. ${ }^{49}$

El departamento, en su nombre y en el de los distritos, procedió a hacer una emisión denominada bonos de la deuda interna municipal unificada de Antioquia (primera emisión). Dicha emisión se hizo por 3463 bonos y el monto total de ellos ascendió a 1196271 en oro colombiano amonedado o su equivalente (Gaceta Departamental de Antioquia, 1934, núm. 4193. Decreto núm. 18 de marzo). El total pertenecía a los herederos del señor Restrepo.

Por último, se ordenó al señor superintendente de Rentas Departamentales para que retuviese de las participaciones de los distritos deudores, en las rentas departamentales, las sumas de dinero que correspondiese a cada uno de ellos, sumas que la Superintendencia de Rentas debería emplear en atender sin demora alguna al oportuno servicio de los bonos.

Por medio del acuerdo logrado, las partes fijaron cuotas que cada una de las entidades municipales deudoras debían pagar mensualmente para el cumplido servicio de sus obligaciones. Se acordó igualmente que el plazo de la amortización total de la deuda por capital e intereses se prorrogaría a 20 años, que empezarían a correr a partir del 1 de julio de 1933 . A su vez, se pactó la reducción de los intereses a $6.6 \%$, los cuales debían ser satisfechos por mensualidades vencidas. ${ }^{50}$

De esta manera, con la reestructuración la deuda con el señor Restrepo pasó de estar en múltiples obligaciones en cabeza de numerosos municipios, con capacidad financiera limitada, a bonos de la deuda interna unificada de Antioquia, respaldados por las rentas de la gobernación. Las rentas estaban así pignoradas en favor de la nueva acreencia. Una vez logrado el marco del acuerdo, cada municipio tuvo que hacer su arreglo individual con la sucesión. Este proceso se llevó a cabo entre junio y septiembre de 1933 .

48 Arreglo entre algunos municipios y los herederos de Emilio Restrepo C. Notaría 2. Escritura núm. 194, 27 de enero de 1934. AHA.

${ }^{49}$ Arreglo entre algunos municipios y los herederos de Emilio Restrepo C. Artículo 13. Notaría 2, Escritura núm. 194, 27 de enero de 1934. AHA.

${ }^{50}$ Artículos 25, 26 y 27. Notaría 2, Escritura núm. 194, 27 de enero de 1934. AHA. 


\section{REFLEXIONES FINALES}

En las primeras décadas del siglo xx el capital privado desempeñó un papel importante en la formación de las principales empresas de servicio público como lo han mostrado Toro (1984) y Botero (2003). Asimismo, este participó en el financiamiento de proyectos de obras públicas en distritos municipales como se ha examinado en el presente texto. ${ }^{51}$

En efecto, entre 1912-1931, según se ha descrito anteriormente, las autoridades locales de numerosos distritos municipales de Antioquia obtuvieron empréstitos con el fin de llevar a cabo proyectos de obras públicas, como la instalación de plantas eléctricas. Dada la importancia relativa del café como producto de exportación, en algunos de los principales municipios cafeteros se instalaron trilladoras con la ayuda de dichos empréstitos.

Los recursos para el financiamiento de las obras, hasta donde se tiene información, procedieron de bancos extranjeros que canalizaron sumas de dinero a través de una casa comercial-bancaria de Medellín, particularmente por medio de uno de sus socios. Dicha firma operaba como intermediaria del capital financiero internacional. Inicialmente, y hasta que comenzó la primera guerra mundial, los señores Restrepo recibieron préstamos de bancos ingleses: entre esos, el Anglo South American Bank y el Commercial Bank of Spanish America. A partir de entonces los recursos los obtuvieron del capital financiero estadunidense.

Lo anterior pone en evidencia varios hechos. En primer lugar, el flujo del capital extranjero a la región y su participación en el desarrollo de obras de infraestructura, que vinculó entidades territoriales de Antioquia con bancos en el exterior. Ese vínculo entre el crédito externo y las localidades se hizo posible por medio de intermediarios financieros, pues, como ha sido descrito por Echavarría (1982), los bancos extranjeros necesitaron de firmas financieras nacionales para ingresar en el circuito financiero local. En el caso concreto de este estudio, se valieron de una casa comercial-bancaria, Hijos de Fernando Restrepo \& Cía., firma que tenía una amplia red de relaciones internas y externas, así como una amplia experiencia en el negocio bancario y financiero.

En este negocio resultaron beneficiados el capital internacional y los intermediarios. Aunque resulta difícil precisar la rentabilidad del negocio para el señor Restrepo, ya que no se conocen los ingresos provenientes del negocio, es posible colegir que, al menos en los años de auge, esa actividad debió serle muy rentable y representarle un incremento de su capital.

En cuanto a los proyectos en los distritos municipales, no se tiene información acerca de cuántas obras se terminaron y se pusieron en funcionamiento y cuántas quedaron inconclusas. Al parecer, algunos proyectos como la construcción de plantas eléctricas y trilladoras, principalmente, se lograron con éxito. Por ejemplo, en 1918 se inauguró una gran trilladora en Pueblo Rico ante la urgente necesidad que tenían los cafeteros (Zapata, 1978). Además, algunos acueductos fueron terminados. No obstante, uno de los problemas que se presentaron en la década de 1930 fue el decaimiento de estos servicios debido a que la difícil situación fiscal no permitía atender su sostenimiento.

Por otro lado, como parecen indicar algunos casos, los empréstitos fueron otorgados sin un orden o prioridad acerca de la conveniencia de la obra o de la capacidad de endeudamiento que tenía cada municipio. Ello fue evidente sobre todo en 1926 y 1927 cuando se concedieron créditos con gran prodigalidad.

${ }^{51}$ Según Botero (2003, p. 228) existió una interrelación entre el capital privado y las principales empresas de servicios públicos de Medellín en las dos primeras décadas del siglo xx. 
Los distritos municipales quedaron endeudados por largo tiempo y el peso de la deuda en las finanzas públicas continuó siendo un problema en los años venideros. En Monografías de Antioquia de $1941^{52}$ se señala claramente el crítico estado en que se encontraban las finanzas públicas de algunos de los distritos municipales, varios de los cuales tenían pignoradas sus rentas.

Este era el caso de varios distritos municipales del Oriente del departamento de Antioquia, los cuales no sólo habían adquirido préstamos con el señor Restrepo, sino que habían participado en un fracasado proyecto financiado por una casa belga para la construcción del Tranvía de Oriente. Esta empresa, constituida en 1924, fue promovida por un político de Marinilla, Román Gómez, buscando un medio de transporte que comunicara a Medellín y a diez distritos del Oriente de Antioquia con el río Magdalena. Con tal fin se contrató un préstamo por 500000 pesos con la firma Evrar Avenirh de Amberes, cuyos representantes en Colombia eran Eduardo López Pumarejo y Juan Dumont. ${ }^{53}$ La empresa fracasó y los distritos municipales debieron asumir la deuda.

La gran expansión del crédito que tuvo lugar en la década de 1920 condujo al fuerte endeudamiento del departamento y de los distritos municipales cuyas graves implicaciones económicas y sociales se sintieron a comienzos de la década de 1930. El secretario de Hacienda de la localidad, explicando el estado de bancarrota en que se encontraba el departamento en 1932, describió lúcidamente la situación: "con una inexperta voracidad de pueblo joven solicitamos y obtuvimos préstamos de todo género, cuyo pago futuro se consideró posible, y cuyas inversiones atropelladamente hechas nos dieron la sensación momentánea de una prosperidad naciente" (Memorias del secretario de Hacienda del Departamento de Antioquia, 1932, p. 4).

\footnotetext{
${ }^{52}$ Libro revisado por Gabriel Arango Mejía y preparado por Cervecería Unión. Recuperado de http://bibliotecadigital.udea.edu.co

53 Véanse Alvear (2020); Sánchez (2007).
} 


\section{APÉNDICE 1}

\begin{tabular}{|c|c|c|c|}
\hline Municipios & $\begin{array}{l}\text { Renta municipios } \\
\text { (pesos oro) }\end{array}$ & $\begin{array}{l}\text { Deuda municipios } \\
\text { (pesos oro) }\end{array}$ & Deuda contra renta \\
\hline Yolombó & 15538 & 5000 & 0.32 \\
\hline Barbosa & 8841 & 5733 & 0.65 \\
\hline Amagá & 7587 & 6000 & 0.79 \\
\hline Caldas & 8897 & 9361 & 1.05 \\
\hline Gomez Plata & 6090 & 6510 & 1.07 \\
\hline Carolina & 5106 & 7073 & 1.39 \\
\hline San Andrés & 3455 & 5354 & 1.55 \\
\hline Frontino & 3491 & 5717 & 1.64 \\
\hline Envigado & 12260 & 20366 & 1.66 \\
\hline San Pedro & 2239 & 4500 & 2.01 \\
\hline Cisneros & 9856 & 20070 & 2.04 \\
\hline Caramanta & 3857 & 8040 & 2.08 \\
\hline Don Matías & 3432 & 7250 & 2.11 \\
\hline La Unión & 1969 & 4646 & 2.36 \\
\hline Zaragoza & 3845 & 9135 & 2.38 \\
\hline Antioquia & 5404 & 15000 & 2.78 \\
\hline La Estrella & 5687 & 16000 & 2.81 \\
\hline Puerto Berrio & 17090 & 50750 & 2.97 \\
\hline Urrao & 5730 & 19000 & 3.32 \\
\hline San Jerónimo & 2476 & 8250 & 3.33 \\
\hline Retiro & 2364 & 8000 & 3.38 \\
\hline Heliconia & 5333 & 18170 & 3.41 \\
\hline Remedios & 5386 & 18800 & 3.49 \\
\hline Ebéjico & 5218 & 19000 & 3.64 \\
\hline Angostura & 3609 & 13250 & 3.67 \\
\hline Nariño & 3631 & 13450 & 3.7 \\
\hline Bello & 8386 & 36610 & 4.37 \\
\hline Ituango & 4460 & 21356 & 4.79 \\
\hline Cañasgordas & 2718 & 13763 & 5.06 \\
\hline Liborina & 2983 & 16350 & 5.48 \\
\hline Titiribí & 6962 & 40000 & 5.75 \\
\hline Guarne & 2855 & 17592 & 6.16 \\
\hline Santa Rosa & 10318 & 65650 & 6.36 \\
\hline Jericó & 8835 & 65255 & 7.39 \\
\hline Fredonia & 15240 & 117861 & 7.73 \\
\hline Concordia & 6321 & 49000 & 7.75 \\
\hline Bolívar & 5525 & 43800 & 7.93 \\
\hline San Carlos & 1233 & 9790 & 7.94 \\
\hline Abejorral & 6227 & 50000 & 8.03 \\
\hline Támesis & 6964 & 56750 & 8.15 \\
\hline Angelópolis & 2027 & 17072 & 8.42 \\
\hline La Ceja & 4239 & 36795 & 8.68 \\
\hline Santa Bárbara & 6153 & 77501 & 12.6 \\
\hline Marinilla & 4056 & 63500 & 15.66 \\
\hline \multirow[t]{2}{*}{ Pueblo Rico } & 4576 & 73261 & 16.01 \\
\hline & 268469 & 1196331 & \\
\hline
\end{tabular}

Fuente: elaboración propia con base en artículos 5 y 10. Notaría 2. Escritura núm. 194, 27 de enero de 1934. AHA. 


\section{LISTA DE REFERENCIAS}

Alvear, J. (2020, octubre 9). La lamentable historia del tranvía de Oriente. Presentado en Conferencia de Ingreso a la Academia Antioqueña de Historia, Medellín, Colombia.

Arango, M. (1977). Café e industria: 1850-1930. Bogotá: Carlos Valencia Editores.

Asamblea de Antioquia (1917). Anales de la Asamblea de Antioquia (Núm. 1).

Asamblea de Antioquia (1931). Sesiones extraordinarias. Carta del presidente del Concejo Municipal (Titiribi) (Núm. 6796).

Asamblea de Antioquia (1932). Actas Asamblea Departamental de Antioquia. Informe de una Comisión (Núm. 10).

Avella, M. (2004). Antecedentes históricos de la deuda externa colombiana. De la paz británica a la paz americana. Revista de Economía Institucional, 6(11), 157-206.

Bejarano, J. A. (1997). El despegue cafetero (1900-1928). En J. A. Ocampo (ed.), Historia económica de Colombia (pp. 173-207). Bogotá: Imprenta Nacional de Colombia.

Bell, P. L. (1921). Colombia manual comercial e industrial. Bogotá: Banco de la República.

Bernal, J. (1984). Las finanzas del sector público central en los años veinte y treinta en Colombia. Coyuntura Económica: Investigación Económica y Social, 14, 129-167.

Botero, F. (2003). La industrialización en Antioquia: Génesis y consolidación, 1900-1930. Colombia: Hombre Nuevo.

Botero, M. M. (1994). El Banco de Antioquia y el Banco de Sucre 1872-1920. En F. Sánchez (ed.), Ensayos de historia monetaria y bancaria de Colombia. Bogotá: Tercer Mundo Editores.

Botero, M. M. (2012). La Banca regional en Colombia (1872-1923): El caso de Antioquía. Revista de la historia de la economía y de la empresa, 6, 77-96.

Brew, R. (1977). El desarrollo económico de Antioquia desde la independencia hasta 1920. Medellín: Banco de la República.

Colombia, Revista Semanal (1922), 2(51).

Contraloría General de la República (1937). Anuario general de Estadística 1936. Bogotá: Imprenta Nacional.

Echavarría, J. J. (1982). La deuda externa colombiana durante los 20s y 30s. Algunas enseñanzas para el presente. Coyuntura Económica, 12(2), 85-119.

Federación Nacional de Cafeteros de Colombia (1932). Censo Cafetero. Colombia: Autor.

Gaceta Departamental de Antioquia (1934a). 4179.

Gaceta Departamental de Antioquia (1934b). 4193.

Gaviria, J. (1923). Monografías de Antioquia. Medellín en 1923. Medellín: Imprenta Oficial de Medellín.

Hanley, A. G. (2005). Native capital: Financial institutions and economic development in Sao Paulo, Brazil, 1850-1920. Stanford: Stanford University Press.

Jaramillo, E. (1932). Memorias de Hacienda. Colombia: Imprenta Nacional.

Memorias del Ministro de Hacienda. Contrato de Financiación de Antioquia (1931). Publicaciones Oficiales.

Memorias del secretario de Hacienda del Departamento de Antioquia (1932). Publicaciones Oficiales.

Memorias del Secretario de Hacienda del Departamento de Antioquia. Unificación de la Deuda Municipal (1934). Publicaciones Oficiales.

Mensajes del gobernador a la Asamblea (1930). Publicaciones Oficiales. 
Ocampo, J. A. (1997). Crisis mundial y cambio estructural (1929-1945). En J. A. Ocampo (ed.), Historia económica de Colombia (pp. 281-330). Bogotá: Imprenta Nacional de Colombia.

Ospina, P. N. (1927). Pedro N. Ospina al Ministro de Gobierno (Núm. C/27, folio 194). Colombia.

Palacio, M. (1979). Café en Colombia: 1890-1970. Una historia monetaria y bancaria de Colombia. Bogotá: Tercer Mundo Editores.

Patiño, A. (1981). La prosperidad al debe y la gran crisis 1923-1935. Bogotá: Banco de la República.

Pérez, J. A. (2012). Auge cafetero y financiación internacional en Colombia 1914-1934. Revista Análisis Internacional, 1(6), 87-121.

Romero, C. A. (1994). La Banca Privada en Bogotá: 1870-1922. En F. Sánchez (ed.), Ensayos de historia monetaria y bancaria de Colombia (p. 297). Bogotá: Tercer Mundo Editores.

Sánchez, D. I. (2007). El Tranvía de Oriente. Una recta imaginada hacia el Magdalena 1924-1942. Medellín: Instituto para el Desarrollo de Antioquia.

Sánchez, F. (1994). Moneda y política monetaria de Colombia. En F. Sánchez (ed.), Ensayos de historia monetaria y bancaria de Colombia (pp. 49-83). Bogotá: Tercer Mundo Editores.

Toro, C. (1984). Inversión privada en servicios públicos: El caso del alumbrado eléctrico de Bogotá y Medellín 1889-1918. Lecturas de Economía, 15, 103-168.

Tovar, B. (1984). La intervención económica del Estado en Colombia 1914-1936. Bogotá: Banco Popular.

Westinghouse Electric \& Manufacturing Company (1924). Silent Sentinels: Protective Relays for AC and DC Systems. Westinghouse Electric \& Manufacturing Company.

Zapata, H. (ed.). (1978). Monografías de Antioquia. Medellín: Cervecería Unión.

Otras fuentes

AHA Archivo Histórico de Antioquia, fondo Notarial, Medellín, Colombia.

AFRH Archivo Fernando Restrepo e Hijos (1885, 1911-1913, 1916). Comunicación personal. Archivo privado.

AGPNo Archivo General Pedro Nel Ospina. ([1919, 1923 -1924]). Comunicación personal. Archivo privado

Diario Oficial, 24 de junio de 1907.

Ley 6 de 1928. Sobre empréstitos, Diario Oficial, 9 de junio de 1928. 